\title{
Outbreak of Salmonella Montevideo associated with a dietary food supplement flagged in the Rapid Alert System for Food and Feed (RASFF) in Germany, 2010
}

P Stöcker (StoeckerP@rki.de)1,2,3, B Rosner ${ }^{3}$, D Werber ${ }^{3}$, M Kirchner $^{4}$, A Reinecke ${ }^{5}$, H Wichmann-Schauer ${ }^{5}$, R Prager6, W Rabsch ${ }^{6}$, C Frank ${ }^{3,7}$

1. Postgraduate Training for Applied Epidemiology (PAE, German Field Epidemiology Training Programme), Robert Koch Institute, Department for Infectious Disease Epidemiology, Berlin, Germany

2. European Programme for Intervention Epidemiology Training (EPIET), European Centre for Disease Prevention and Control (ECDC), Stockholm, Sweden

3. Robert Koch Institute, Department Infectious Disease Epidemiology, Berlin, Germany

4. Governmental Institute of Public Health of Lower Saxony, Hannover, Germany

5. Federal Institute for Risk Assessment, Berlin, Germany

6. National Reference Centre for Salmonella and other Enterics, Robert Koch Institute, Wernigerode Branch, Germany

7. Institute for Hygiene and Public Health, University of Bonn, Germany

Stöcker P, Rosner B, Werber D, Kirchner M, Reinecke A, Wichmann-Schauer H, Prager R, Rabsch W, Frank C. Outbreak of Salmonella Montevideo associated with a dietary food supplement flagged in the Rapid Alert System for Food and Feed (RASFF) in Germany, 2010.

Euro Surveill. 2011;16(50):pii=20040. Available online: http://www.eurosurveillance.org/ViewArticle.aspx?Articleld=20040

Article published on 15 December 2011

In March 2010 the Rapid Alert System for Food and Feed (RASFF) was used to inform about Salmonella Montevideo in a herbal food supplement, formulated in capsules, distributed under a Dutch label in Germany. Simultaneous to the first RASFF notice, in the last two weeks of March 2010 an unusual number of 15 infections with $S$. Montevideo was notified within the electronic reporting system for infectious diseases at the Robert Koch Institute. Adult women (median age: 43, range: 1-90 years) were mainly affected. An outbreak was suspected and the food supplement hypothesised to be its vehicle. Cases were notified from six federal states throughout Germany, which required efficient coordination of information and activities. A casecontrol study $(n=55)$ among adult women showed an association between consumption of the specific food supplement and the disease (odds ratio (OR): $27.5,95 \%$ confidence interval $(\mathrm{Cl})$ : 3.1-infinity, $\mathrm{p}$-value $=0.002$ ). Restricting the case-control study to the period when the outbreak peaked (between 29 March and 11 April 2010) resulted in an OR of 43.5 (95\% Cl: 4.8-infinity, $\mathrm{p}$-value $=0.001$ ). Trace-back of the supplement's main ingredient, hemp seed flour, and subsequent microbiological testing by pulsed-field gel electrophoresis supported its likely role in transmission. This outbreak investigation illustrates that information from RASFF may aid in hypothesis generation in outbreak investigations, though likely late in the outbreak.

\section{Introduction}

Launched in 1979, the Rapid Alert System for Food and Feed (RASFF) was put in place to provide food and feed control authorities within the European Union (EU) with an effective tool to exchange information about measures taken in response to serious risks detected in relation to food or feed [1]. Information exchange via RASFF is required, if the suspected food or feed product has been traded or distributed across internal EU borders. The system is well established [2] and a rapid exchange is supposed to allow all Member States to verify immediately whether they are commonly affected by a problem. Whenever the product is on sale to consumers, it is the responsibility of the Member States' authorities to take all necessary measures such as withdrawing or recalling food or feed products from the market in order to protect consumers' health, as well as informing the public.

In February 2010, a German federal state laboratory conducted a chemical-toxicological as well as microbiological investigation of the remainder of a food supplement after a female consumer of this supplement had developed a rash. In the course of the investigation, Salmonella Montevideo was unexpectedly found. The food supplement formulated in capsules, was produced by a German company but distributed under a Dutch label. It had been marketed online and via teleshopping to menopausal and postmenopausal women. On 27 March 2010, a nationwide recall and withdrawal of the product, limited to specific batches, was conducted by company A via individual post and telephone-calls to consumers in Germany registered through points of sale of the product. Additionally, recall and public warning were communicated via the teleshopping channel and various print media. On 29 March 2010, an RASFF alert notification informed about $S$. Montevideo in the withdrawn food supplement distributed under a Dutch label in Germany, followed by several additional notifications in RASFF throughout subsequent weeks with supplemental information on 
laboratory test results and trade routes of the product and its ingredients, as well as measures taken in the affected federal states in Germany.

Simultaneous to the first RASFF notice, the electronic reporting system for infectious diseases at the Robert Koch Institute (RKI) showed an unusual increase in the number of salmonellosis notifications due to $S$. Montevideo. In March and April 2010 (date of disease onset - where available - between 28 March and 12 April), an unusual number of 15 infections were notified from six federal states throughout Germany. Most of this excess appeared to affect adult women.

Infections with Salmonella are a major cause of bacterial food-borne diarrhoea in humans. However, throughout the past years, only a few reports were published on food-borne outbreaks of Salmonella infections due to the serovar Montevideo [3-9]. The endemic level of S. Montevideo in Germany is low: In 2008 and 2009, 65 and 38 respective $S$. Montevideo infections were notified throughout the entire year, corresponding to $0.1 \%$ of all human salmonellosis notified within the German electronic reporting system in these years [10].

Given the RASFF notice, and the increase in case numbers, an investigation was initiated at RKI to identify the role of the food supplement in this outbreak, and to assess the usefulness of RASFF for retrospective outbreak explanation.

\section{Methods \\ Descriptive epidemiology}

In Germany, infections with $S$. Montevideo infections are legally notifiable within the category of non-typhoidal salmonelloses [11]. Case-definition is based on characteristic symptoms and laboratory confirmation, or epidemiological linkage to another laboratory-confirmed case [12].

A detailed exploratory questionnaire specifically designed by RKI experts was administered by telephone from 7 to 13 May 2010 to females with S. Montevideo infections notified within the national reporting system between 1 January and 28 March 2010. Data collection encompassed onset and nature of clinical symptoms and their duration, hospitalisation and regular intake of any medication including antacids and prescription of antimicrobial medication for salmonellosis, environmental and food exposures focusing on foods previously associated with outbreaks of $S$. Montevideo in other countries $[5,7,13]$. This included salami, alluding to a salami and pepper mediated $S$. Montevideo outbreak in the United States, published concurrently to this outbreak [6]. Furthermore, we inquired about animal contact, travel history, other underlying medical conditions and additional cases of diarrhoea or vomiting in the household in the seven days before symptom onset. In addition, cases were asked about consumption of food supplements in general, and about consumption of the specific, RASFF-flagged food supplement of company A. As hemp seed flour was one of the main ingredients of the food supplement, we also asked about exposure to places of sale of hemp seed flour or products containing it. Furthermore local health departments were asked to refer any remaining specific food supplement from company A, which was mentioned in the RASFF, from new cases' households, to a food safety laboratory for microbiological testing.

\section{Case-control study}

A case-control study was initiated and coordinated by RKI to test the hypothesis that the specific food supplement from company $A$ was associated with $S$. Montevideo-infections with disease onset in March or April 2010.

For this study a case was defined as a female resident in Germany, aged 20 years or more, notified between 1 and 25 April 2010 to the national electronic reporting system for communicable diseases, and for whom $S$. Montevideo was cultured from stool. Cases were excluded if they reported having had contact with a person with diarrhoea in the seven days prior to symptom onset because they could have arisen by secondary person-to-person transmission. Controls were identified by a two-stage sampling design: first, in federal states where cases occurred, counties were randomly selected with a probability of inclusion proportional to their population size. Second, the so chosen counties were asked to provide randomly 60 to 80 addresses of women aged between 20 and 80 years from population registries, for whom telephone numbers were looked up in public directories. Controls were frequencymatched to cases by state and age with a ratio of cases to controls of 1:4. A hypothesis-testing questionnaire was designed focussing mainly on the consumption of the food supplement from company $A$ for the year 2010 up to the date of interview. We asked for underlying chronic diseases and regular intake of medicines. In addition, cases were asked about clinical symptoms around the Easter holidays (29 March-10 April) and duration of illness. Study participants were interviewed by telephone by RKI staff.

\section{Data analysis}

For descriptive analysis we calculated absolute numbers and proportions. All exposures were tested for association with the outcome variable (S. Montevideo infection) using univariable and multivariable exact logistic regression. We report odds ratios (OR) and $95 \%$ confidence intervals $(\mathrm{Cl})$. All reported $\mathrm{p}$-values are two sided and p<0.05 was considered significant. Data were analysed with Stata, Version 11.0, StataCorp LP, Texas, USA.

\section{Product tracing}

Following the RASFF notification in March 2010, the investigation by food and veterinary authorities was tailored to trace the contaminated consignment. Detailed investigations according to the legal requirements regarding production and supply of the suspected 
food supplement were carried out by affected federal states. Outcome of investigations and measures taken in Germany were communicated via RASFF.

\section{Microbiological investigation}

and molecular subtyping

Cases' stool samples, as well as samples of the food supplement, its raw ingredients and environmental samples from production facilities were investigated by various laboratories for the presence of $S$. Montevideo. For comparison of $S$. Montevideo patterns, pulsed-field gel electrophoresis (PFGE) was used according to Ribot et al. [14]. The PFGE analysis included S. Montevideo isolates that were sent by laboratories in Germany to the National Reference Centre (NRC) for Salmonella and other Enterics between March and May 2010. The $S$. Montevideo isolates for the PFGE analysis consisted of: (i) isolates from stool specimens of two outbreak cases, (ii) isolates from respective stool samples of two cases who were unrelated to the outbreak, (iii) one isolate from the food supplement from an outbreak case's household, (iv) one isolate from an environmental sample from the facility where the food supplement was produced and (v) one isolate arising from biosolids retrieved during an official process control of a biogas plant.

\section{Results}

\section{Descriptive epidemiology}

In 2010, the RKI received 37 reports of $S$. Montevideo until 9 May with a peak between 29 March and 11 April, 31 with known date of symptom onset (Figure 1).
Six of 16 German federal states reported S. Montevideo cases with onset of disease from week one through 18 (4 January-9 May). In the preceding five years, the mean case number per week of $S$. Montevideo infections for the same period had been one to two per week (background rate). In the two weeks between 29 March and 11 April 2010, however, 15 cases were registered. This peak was mainly due to an increase of reported $S$. Montevideo in adult women ( $>18$ years of age), with 10 infections in women versus five infections in men. In this period, the median age of women was 43 (range: 1-90 years) and the median age of men was 75 (range: $6-82)$.

Thirteen exploratory questionnaires were completed. An additional complete questionnaire was obtained by a proxy of the local health department who had already interviewed a patient unfit for further questioning. Onset of symptoms ranged from 21 March through 22 April 2010. Of the 14 persons from whom complete information was available, four were excluded as possible secondary cases. Four of the 10 remaining women indicated consumption of the food supplement from one of the implicated batches as of the end of March 2010, when they had received a notice from the distributor. One of the interviewed women was of advanced age (90 years) and could not exclude that she may have consumed the product even after receiving the notice. All four women had symptom onset between 29 March and 4 April 2010 (week 13) and had bought the product via teleshopping in January or February 2010. All of them consumed the product for at least four weeks with a daily dose of two capsules.

\section{FIGURE 1}

Reported cases of Salmonella Montevideo with known date of disease onset, Germany, 4 January-9 May 2010 (n=31)

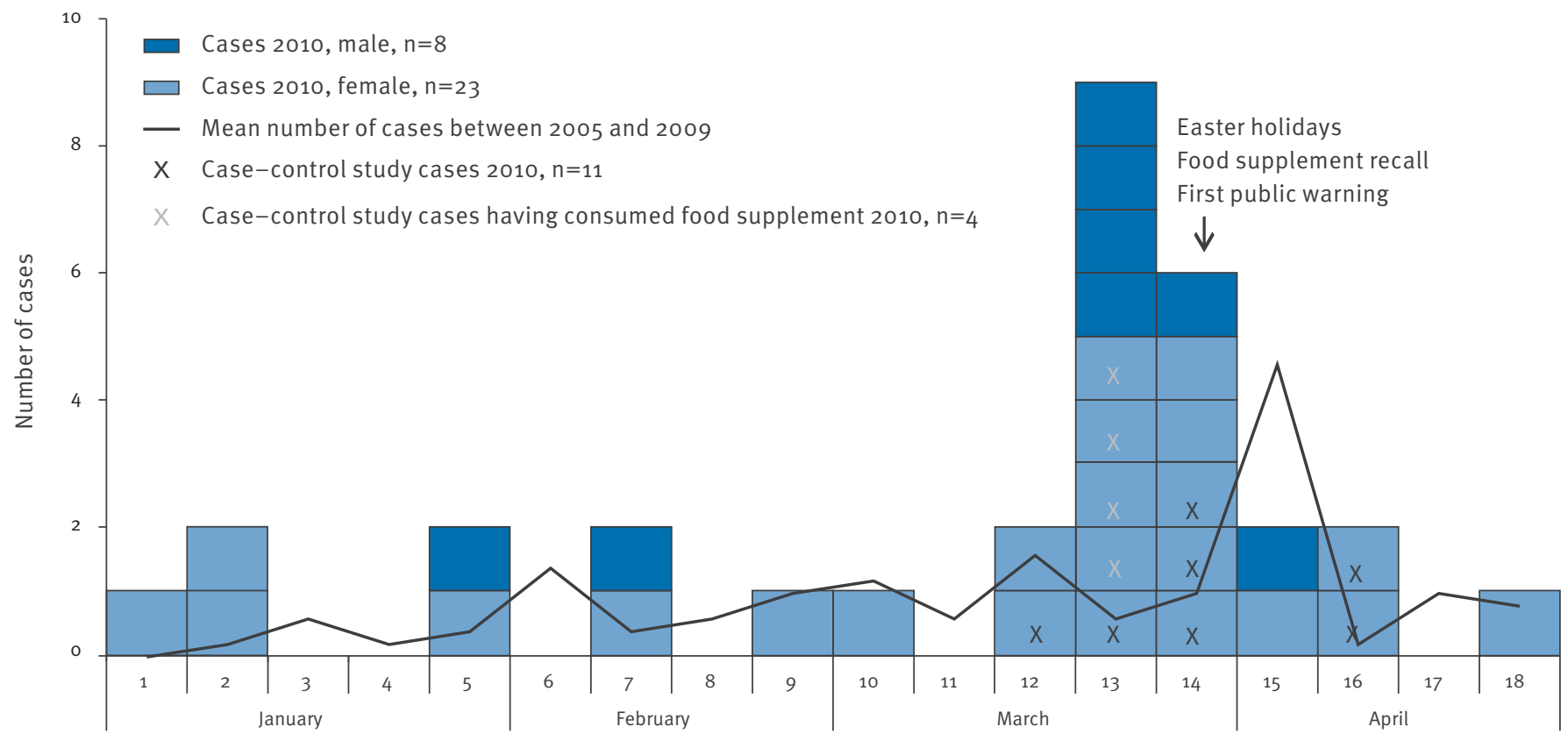

Week of disease onset 2010 
Other potentially relevant exposures included consumption of peppered salami products $(n=2)$ as well as fried or boiled eggs $(n=8)$. Peppered salami was not investigated further due to low exposure proportion. Even though high egg consumption was likely due to the Easter holidays (29 March-10 April), this was included in the case-control study. Of all investigated cases, none remembered buying hemp seed flour or other products made from it.

\section{Case-control study}

Eleven cases (10 previously explored plus one additional case) and 44 controls were enrolled in the frequency-matched case-control study. The median age of cases was 56 years (range 20-90) and that of controls was 54.5 years (range 20-80). Reported symptoms ranged from diarrhoea (nine cases - none reported bloody diarrhoea), fever $>38.5^{\circ} \mathrm{C}$ (three cases) and vomiting (three cases). Three cases were hospitalised for five, seven and 10 days, respectively.

In univariable analysis only consumption of the specific food supplement and taking of medicines were significantly associated with $S$. Montevideo infection (Table). In a multivariable model including both risk factors, the specific food supplement was significantly associated with infection (OR: 19.2, 95\% Cl: 5.61-infinity, $p$-value $=0.014$ ) but not taking of medicines (OR: $3.79,95 \% \mathrm{Cl}: 0.26-18.55, \mathrm{p}$-value $=0.267)$. In a subanalysis restricted to cases with a date of disease onset between 29 March and 11 April, 2010 ("excess period") the association of disease and the food supplement was even stronger (OR: 43.5 , 95\% Cl: 4.81infinity, $p$-value $=0.001$ ). Four cases (one hospitalised) consumed the supplement but none of the controls. While the median age of all cases in the case-control study was 56 years (range 20-90), the median age of cases having consumed the specific food supplement was 65.5 years (range 47-90, difference not statistically significant in Kruskal-Wallis-test).There was no statistical significance on egg consumption (data not shown).

\section{Product tracing}

Product trace investigation revealed the trade route of ingredients and manufactured product. The main ingredient of the food supplement, hemp seed flour, was produced from hemp seed imported from China via the Netherlands by a German company (German State A). Later the seeds were milled in an oil mill (German State B) and the flour delivered to a wholesaler (German State A) who sold it to the food supplement producer (German State C), two bakeries in the south of Germany and a health food store in a city in the north of Germany. In addition, a fraction of the same batch of flour was exported to Slovenia.

\section{Environmental investigation}

Between February and May 2010 a total of 11 samples were taken for microbiological testing, with $S$. Montevideo found in six (54\%) of the samples: in opened packages of food supplement from two cases' households (implicated lots), in two samples of food supplement (implicated lots) that had not been sold, in samples of hemp flour from opened and closed flour sacks at the production facility, as well as in a dust sample from the oil mill. Negative were a retain sample at the production facility (implicated lot), various hemp flour based products at the wholesale level, and other product and environmental samples from the oil mill.

\section{Microbiological investigation \\ and molecular subtyping}

Two respective $S$. Montevideo isolates from stool specimens from two female outbreak cases who were included in the case-control study, one S. Montevideo isolate from the food supplement from a case's household, as well as an isolate from the oil mill in German State B were analysed by PFGE, together with $S$. Montevideo isolates from sources apparently unrelated to the outbreak, including two other human stool samples and a sample derived from bio-solids from a biogas plant.

The PFGE profiles of $S$. Montevideo isolates from the leftover of the food supplement of the case's household, the two female human case isolates and the isolate from the oil mill were indistinguishable (Figure 2).

\section{Discussion}

We describe an investigation of a disseminated outbreak of $S$. Montevideo infections where cases

\section{TABLE}

Risk factors for cases $(\mathrm{n}=11)$ and controls $(\mathrm{n}=44)$ of Salmonella Montevideo-associated illness in Germany, 29 March-11 April 2010

\begin{tabular}{|l|c|c|c|c|}
\hline Exposure or underlying condition & $\begin{array}{c}\text { Cases } \\
\mathrm{n} / \mathrm{N}^{\mathrm{a}}\end{array}$ & $\begin{array}{c}\text { Controls } \\
\mathrm{n} / \mathrm{N}^{\mathrm{a}}\end{array}$ & Odds ratio $^{\mathrm{b}}$ & 95\% Confidence interval $^{\mathrm{b}}$ \\
\hline Specific food supplement & $4 / 11$ & $0 / 43$ & 27.5 & $3.15-\infty$ \\
\hline Other food supplements & $5 / 10$ & $20 / 44$ & 3.3 & 0.001 \\
\hline Taking of medicines & $8 / 9$ & $21 / 44$ & 8.7 & 0.092 \\
\hline Any chronic disease & $5 / 9$ & $15 / 44$ & 2.4 & 0.030 \\
\hline
\end{tabular}

a Total number of cases for whom information was available.

b Univariable exact logistic regression. 
were ascertained in six German federal states. Epidemiological and microbiological evidence indicates that a herbal food supplement was a vehicle of infection and that hemp seed flour was most likely the contaminated ingredient, as a sample of hemp flour at the production facility tested positive for S. Montevideo. This is the first time that a RASFF notification could be connected to a human disease outbreak in Germany, albeit a small outbreak. A literature search provided only one other instance, where this had been achieved in another country [15]. Thus, food safety information of contaminated products can be a valuable source to public health authorities for hypothesis generation in outbreaks, provided that they are communicated in a timely manner.

Salmonella infections after consumption of food supplements are rarely noticed. They were first reported in 1966 in Tennessee, United States [16]. The food supplement in this outbreak tested positive both at the production site and in cases' households. Yet, a retain sample of an implicated lot had tested negative, demonstrating that tests on retain samples, which are often not representative of the entire lot, may convey a false sense of security. Hemp seed flour at the producer of the food supplement was confirmed as contaminated. In addition, the outbreak strain was also detected in dust samples of the oil mill. The source of the contamination before or at the oil mill remains elusive. There were no other links between hemp seed flour distributed to other customers (e.g. the bakeries) and additional cases. The distributor of the contaminated batches of hemp seed and hemp flour impounded all warehouse stocks of hemp seed and their derivates on 26 March. Some deliveries of hemp flour within Germany as well as to Slovenia took place beforehand. No resulting cases of infection were apparently noted in Slovenia.

\section{FIGURE 2}

Pulsed-field gel electrophoresis analysis (XbaI) of Salmonella Montevideo isolates obtained by the National Reference Centre during the outbreak-period, Germany, March-May 2010 (n=7)

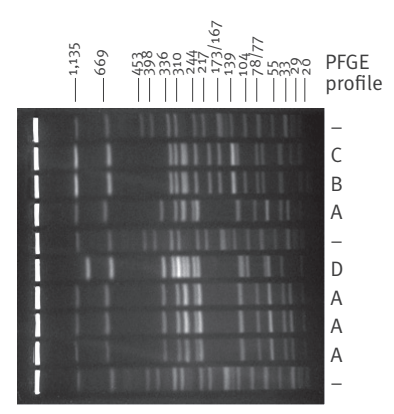

Sample description

Molecular marker

Stool sample human (sex unspecified)

Stool sample human (male)

Stool sample case-control study case (female) Molecular marker

Sample from official process control from a biogas plan Stool sample case-control study case (female) Leftover from case's suspected food supplement Dust sample from the implicated oil mill Molecular marker

PFGE: Pulsed-field gel electrophoresis.

The molecular marker fragments' sizes in kilobase pairs are shown on top of the picture.

Source of data: National Reference Centre for Salmonella and other Enterics, Robert Koch Institute, Wernigerode Branch, Germany.
Supplement consumption in this outbreak does not explain the increase in the number of cases entirely, leaving the possibility of more vehicles. Due to the low numbers of cases in exploration and the case-control study, we could not identify further risk factors. As the food supplement hypothesis could not have affected men, we cannot explain their infections directly, though we did not investigate if some of them were secondary cases to women infected by the food supplement. Interestingly, their greatest case excess was between 29 March and 4 April, when the four female cases explained by the supplement fell ill. Differential exposure recall of cases and controls is an inherent source of bias in case-control studies. However, taking such a supplement should be a well-remembered exposure, as the purchase would have required determined action and the consumption would have been regular over a longer period of time. The bias introduced in control selection by the requirement of a listed telephone number is recognised, but not thought to have made a significant difference in this study in view of the mainly affected age group.

The first evidence towards RASFF notification and subsequent product recall consisted of a first positive test result obtained from an official food control laboratory in one federal state due to a consumer's complaint. As this sample originated from an opened food supplement package the positive finding triggered further microbiological investigations of the product and its ingredients to render the evidence undisputable

In Europe, public warnings and product recalls are based on statutory instruments regarding the food legislation [17]. Producer and retailer of the food supplement and the ingredients were ascertained by product trace-back. The warning and product recall were issued at the time state laboratories found $S$. Montevideo in unopened packages and in the raw ingredients at the producer.

While investigations of the food safety authorities were thorough, without delay, and strictly following regulations, it is worth noting that the process from the beginning of the analysis of the first positive sample from an opened package to the recall took more than five weeks. In potential outbreak situations, strength of evidence for a suspected food product ought to be weighed against the potential harm to the consumers posed by the suspected food.

Interestingly, in the end there was no international aspect to this outbreak (as the Dutch label on the product did not correspond to sales in the Netherlands). Nevertheless it was only the RASFF directing the attention of German public health authorities to this contaminated product. Information from RASFF may aid in hypothesis generation investigations in addition to it being useful for early identification of emerging food safety hazards [18]. In Germany, unfortunately, currently there is no general requirement to communicate 


\section{non-international food contamination events to the public health authorities.}

\section{Competing interests}

The authors declare that they have no competing interests.

\section{Acknowledgments}

We thank Dr. Manuel Dehnert for statistical support. We wish to sincerely acknowledge all women interviewed in the course of our investigation. Furthermore we are grateful to the local health departments involved for their support in contacting case patients as well as the local food authorities for their information on public health action in counties in response to this outbreak. We also thank the National Reference Laboratory (NRL) for the Analysis and Testing of Zoonoses (Salmonella) at the Federal Institute for Risk Assessment for their provision of data and specimens in this investigation. Finally we thank all registration offices providing contact data for the selection of controls.

\section{References}

1. European Commission. Food and Feed Safety. Rapid Alert System for Food and Feed. [Acessed 17 June 2010]. Available from: http://ec.europa.eu/food/food/rapidalert/index_en.htm

2. Petróczi A, Taylor G, Nepusz T, Naughton DP. Gate keepers of EU food safety: four states lead on notification patterns and effectiveness. Food Chem Toxicol. 2010;48(7):1957-64.

3. Dominguez M, Jourdan-Da Silva N, Vaillant V, Pihier N, Kermin C, Weill FX, et al. Outbreak of Salmonella enterica serotype Montevideo infections in France linked to consumption of cheese made from raw milk. Foodborne Pathog Dis. 2009;6(1):121-8.

4. Hamada K, Tsuji H, Oshima K.Salmonella serovar montevideo involved in a food poisoning outbreak at a club for elderly persons in April 2002 in Hyogo Prefecture. Jpn J Infect Dis. 2002;55(5):176-7.

5. Patel MK, Chen S, Pringle J, Russo E, Viñaras J, Weiss J, et al. A prolonged outbreak of Salmonella Montevideo infections associated with multiple locations of a restaurant chain in Phoenix, Arizona, 2008. J Food Prot. 2010;73(10):1858-63.

6. Salmonella montevideo infections associated with salami products made with contaminated imported black and red pepper -.- United States, July 2009-April 2010. MMWR Morb Mortal Wkly Rep. 2010;59(50):1647-50.

7. Centers for Disease Control and Prevention (CDC). Investigation Update: Multistate Outbreak of Human Salmonella Montevideo Infections. Update for May 4, 2010 (FINAL update). Atlanta: CDC. [Acessed 17 June 2010]. Available from: http://www.cdc. gov/salmonella/montevideo/index.html

8. Elson R, Outbreak control team. National increase in human Salmonella Montevideo infections in England and Wales: March to June 2006. Euro Surveill. 2006;11(26):pii=2985. Available from: http://www.eurosurveillance.org/ViewArticle. aspx?Articleld $=2985$

9. Harada T, Sakata J, Kanki M, Seto K, Taguchi M, Kumeda Y. Molecular Epidemiological Investigation of a Diffuse Outbreak Caused by Salmonella enterica Serotype Montevideo Isolates in Osaka Prefecture, Japan. Foodborne Pathog Dis. 2011;8(10):1083-8.

10. Robert Koch-Institute (RKI). SurvStat. Berlin:RKI. [Accessed 17 Jun 2010]. Available from: http://www3.rki.de/SurvStat/

11. Krause G, Altmann D, Faensen D, Porten K, Benzler J, Pfoch T et al. SurvNet electronic surveillance system for infectious disease outbreaks, Germany. Emerg Infect Dis. 2007;13(10):1548-55.

12. Robert Koch Institut (RKI). Falldefinitionen des Robert KochInstituts zur Übermittlung von Erkrankungs- oder Todesfällen und Nachweisen von Krankheitserregern, Ausgabe 2007 [Case definitions for the surveillance of notifiable infectious diseases in Germany]. Berlin:RKI. 2007. [Acessed 17 June 2010]. German. Available from: http://www.rki.de/cln_160/nn_200710/DE/ Content/Infekt/IfSG/Falldefinition/Falldefinition,templateld=ra w, property=publicationFile.pdf/Falldefinition.pdf
13. Elviss NC, Little CL, Hucklesby L, Sagoo S, Surman-Lee S, de Pinna $E$, et al. Microbiological study of fresh herbs from retail premises uncovers an international outbreak of salmonellosis. Int J Food Microbiol. 2009;134(1-2):83-8.

14. Ribot EM, Fair MA, Gautom R, Cameron DN, Hunter SB, Swaminathan B, et al. Standardization of pulsed-field gel electrophoresis protocols for the subtyping of Escherichia coli 0157:H7, Salmonella, and Shigella for PulseNet. Foodborne Pathog Dis. 2006;3(1):59-67.

15. Emberland KE, Ethelberg S, Kuusi M, Vold L, Jensvoll L, Lindstedt BA, et al. Outbreak of Salmonella Weltevreden infections in Norway, Denmark and Finland associated with alfalfa sprouts, July-October 2007. Euro Surveill. 2007;12(48):pii=3321. Available from: http://www. eurosurveillance.org/ViewArticle.aspx?Articleld=3321

16. McCall CE, Collins RN, Jones DB, Kaufmann AF, Brachman PS. An interstate outbreak of salmonellosis traced to a contaminated food supplement. Am J Epidemiol. 1966;84(1):32-9.

17. European Union (EU). Food and feed safety. EU. [Acessed 17 June 2010]. Available from: http://europa.eu/ legislation_summaries/consumers/consumer_information/ f80501_en.htm

18. Kleter GA, Prandini A, Filippi L, Marvin HJ. Identification of potentially emerging food safety issues by analysis of reports published by the European Community's Rapid Alert System for Food and Feed (RASFF) during a four-year period. Food Chem Toxicol. 2009;47(5):932-50. 